\title{
Winter precipitation and cyclones in the Mediterranean region: future climate scenarios in a regional simulation
}

\author{
P. Lionello ${ }^{1}$ and F. Giorgi ${ }^{2}$ \\ ${ }^{1}$ University of Salento, Lecce, Italy \\ ${ }^{2}$ ICTP, Trieste, Italy
}

Received: 5 March 2007 - Revised: 6 July 2007 - Accepted: 22 October 2007 - Published: 16 November 2007

\begin{abstract}
Future climate projections show higher/lower winter (Dec-Jan-Feb) precipitation in the northern/southern Mediterranean region than in present climate conditions. This paper analyzes the results of regional model simulations of the A2 and B2 scenarios, which confirm this opposite precipitation change and link it to the change of cyclone activity. The increase of the winter cyclone activity in future climate scenarios over western Europe is responsible for the larger precipitation at the northern coast of the basin, though the bulk of the change is located outside the Mediterranean region. The reduction of cyclone activity inside the Mediterranean region in future scenarios is responsible for the lower precipitation at the southern and eastern Mediterranean coast.
\end{abstract}

\section{Introduction}

Previous studies, based both on global and regional simulations show opposite changes of winter (Dec-Jan-Feb) precipitation in different part of the Mediterranean region (Giorgi and Lionello, 2007). In most simulations, precipitation is projected to increase in a relatively narrow band in the northern part and to decrease in the rest, with very large reductions in some areas at the western (Morocco) and eastern (Middle Est) border of the Mediterranean region. Figure 1 shows the projected percentage precipitation change according to the MGME (Multi Global Model Ensemble) for the A2 (top) and B1 (bottom) scenarios. These public data, which are stored at the Program for Climate Model Diagnosis and Intercomparison (PCMDI, http://www-pcmdi.llnl.gov), include the results of a large set of global climate simulations carried out with different models by about 20 research groups for the 20th and 21st century under different greenhouse gas forcing scenarios as a contribution to the fourth

Correspondence to: P. Lionello

(piero.lionello@unile.it)
Assessment Report (AR4) of the Intergovernmental Panel on Climate Change (IPCC). The transition line between positive and negative change crosses the northern part of the Mediterranean region, and its position depends little on the emission scenario, while the intensity of the negative (positive) change in the southern Mediterranean (central and northern Europe) dramatically increases with the emission level.

This study analyzes three 30-year regional climate simulations, one for present day conditions (1961-1990) (CTR experiment) and two for future conditions (2071-2100) carried out with the regional climate model RegCM under the IPCC A2 and B2 emission scenarios. The A2 is a high emission scenario, lying towards the high end of the IPCC range, while the B2 is a low emission scenario lying towards the low end of the range.

The aim of this study is to discuss the link between changes of winter precipitation and of cyclonic activity in this regional simulation for producing a consistent overall picture of climate change projection for both quantities in the Mediterranean area.

\section{The RegCM model: present climate simulation}

In this study, the RegCM model grid spacing is $50 \mathrm{~km}$ and the model domain covers the European region and adjacent oceans. The model is driven at the lateral boundaries by meteorological fields from the Hadley Centre global atmospheric model HadAM3H $(1.25 \times 1.875$ lat-lon horizontal resolution). Sea surface temperatures (SSTs) are from corresponding simulations with the Hadley Centre global coupled model HadCM3. For more information on the model and for a general discussion of the simulations, the reader is referred to Giorgi et al. (2004a, b), for the discussion of the cyclone climate change signal to Lionello et al. (2007).

Figure 2 compares the winter CRU (Climate Research Unit, East Anglia University, (New et al., 2000)) and the CTR

Published by Copernicus Publications on behalf of the European Geosciences Union. 

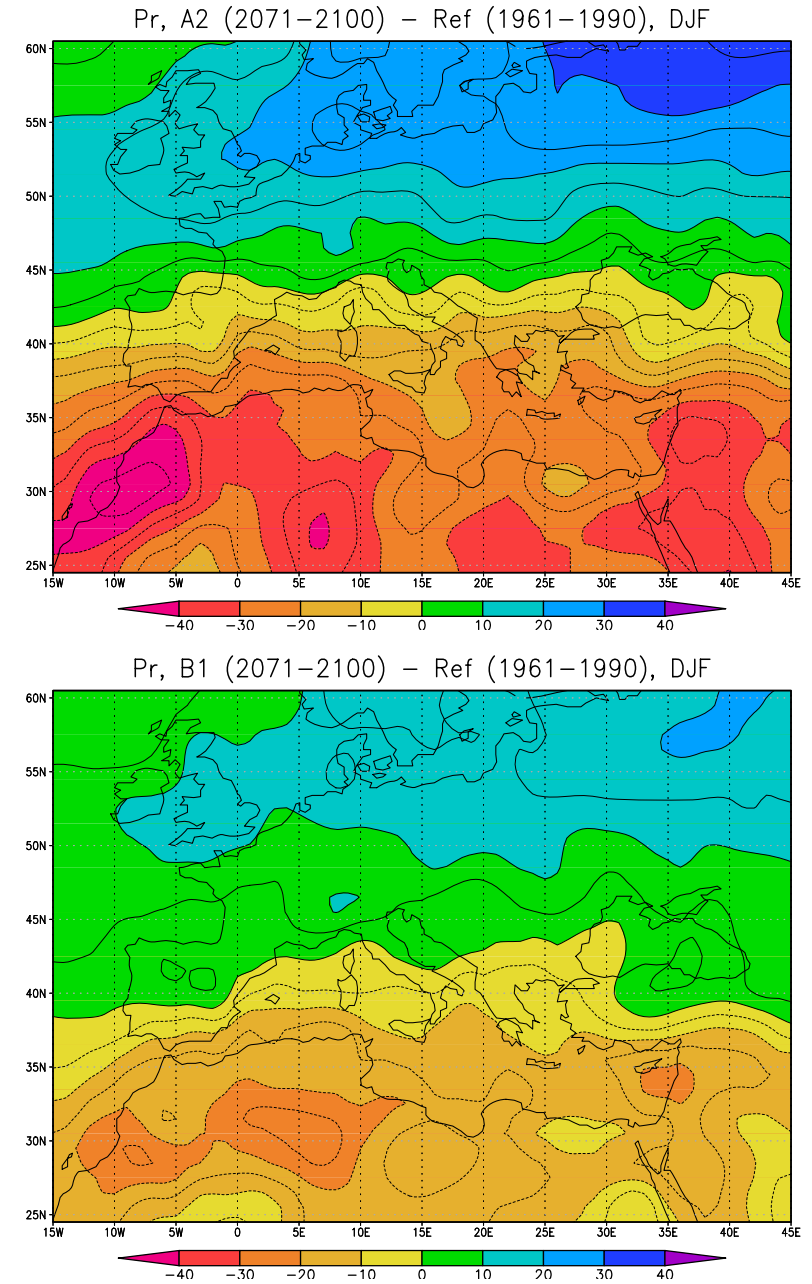

Fig. 1. Winter (Dec-Jan-Feb) multi model average (MGME) precipitation percentage change in the Mediterranean region: A2 scenario minus present climate (top) and B1 scenario minus present climate (bottom).

simulation and it shows the capability of the RegCM model to reproduce correctly the observed climatology, including the maxima along the coasts and on the Alps, and the drier interior areas, although the maxima are underestimated, especially along the western Greek and Turkish coasts.

The cyclone activity is analyzed using a cyclone trajectory identification algorithm and computing the SLP (Sea Level Pressure) standard deviation. Both methods are applied to the SLP fields which have been pre-processed with a band-pass (1-7 day) Lanczos digital filter. The strong features of the band-pass filtered SLP standard deviation (here called synoptic signal) maps are often called storm tracks in the litterature.

Figure 3 shows the synoptic signal of the ERA-40 (ECMWF Re-Analysis, Simmons and Gibson, 2000) and of the CTR simulation. The comparison shows a good quanti-

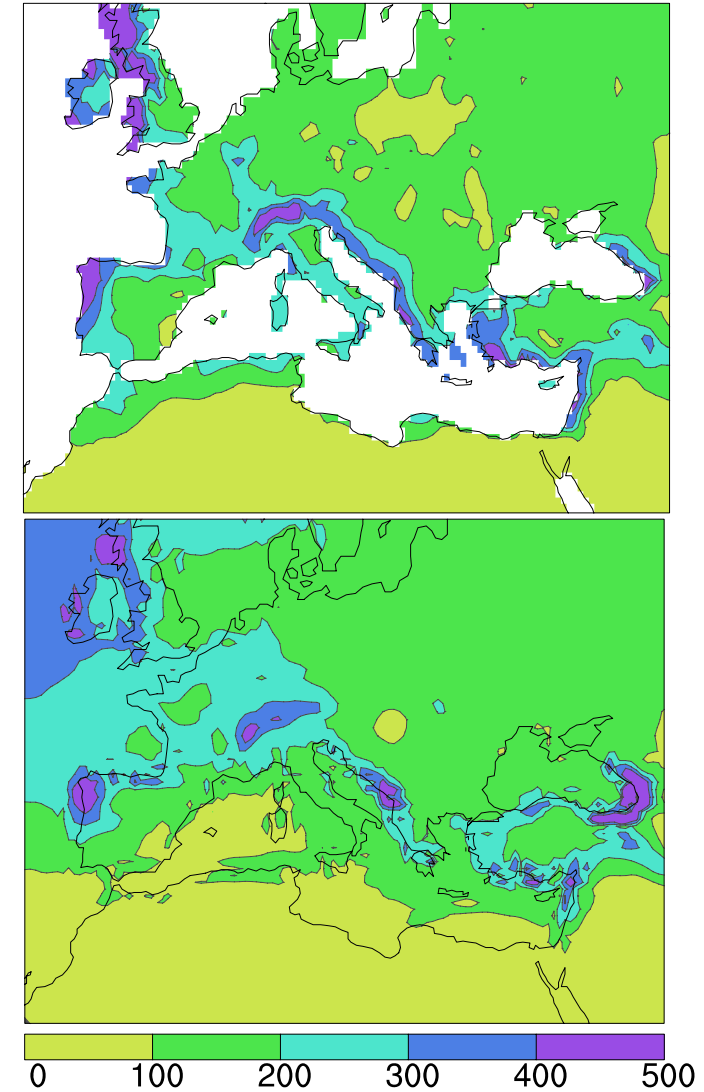

Fig. 2. Winter precipitation according to the CRU data (top) and to the CTR simulation of the RegCM model (bottom). Units: mm.

tative agreement over large parts of the Mediterranean area, except over Turkey. There is a tendency of the CTR simulation to overestimate the synoptic signal mostly outside the Mediterranean region over eastern Europe (East of $20 \mathrm{E}$ longitude, except over Greece) and the Black Sea.

The identification algorithm produces a list of cyclones, with the SLP minima positions and values. The tracking method (Lionello et al., 2002) is based on partitioning of the slp fields in depressions by the identification of sets of steepest descent paths leading to the same slp minimum. All the points crossed by a path leading to the same minimum are assigned to the same depression. Subsequently, any small depression is merged into the closest large size depression. A trajectory, obtained by joining the location of the same low pressure center in successive maps, is associated with the evolution of each depression. The procedure results in a trajectory, an initial and final point, a sequence of pressure minima, and of areas covered by the cyclone.

Figure 4 shows the density of cyclone centers deeper than $15 \mathrm{hPa}$ in the band-pass filtered ERA- 40 and the CTR simulation fields. The comparison between the two figures shows that the CTR simulation overestimates the number of cyclones over an area stretching from central Europe to Turkey 

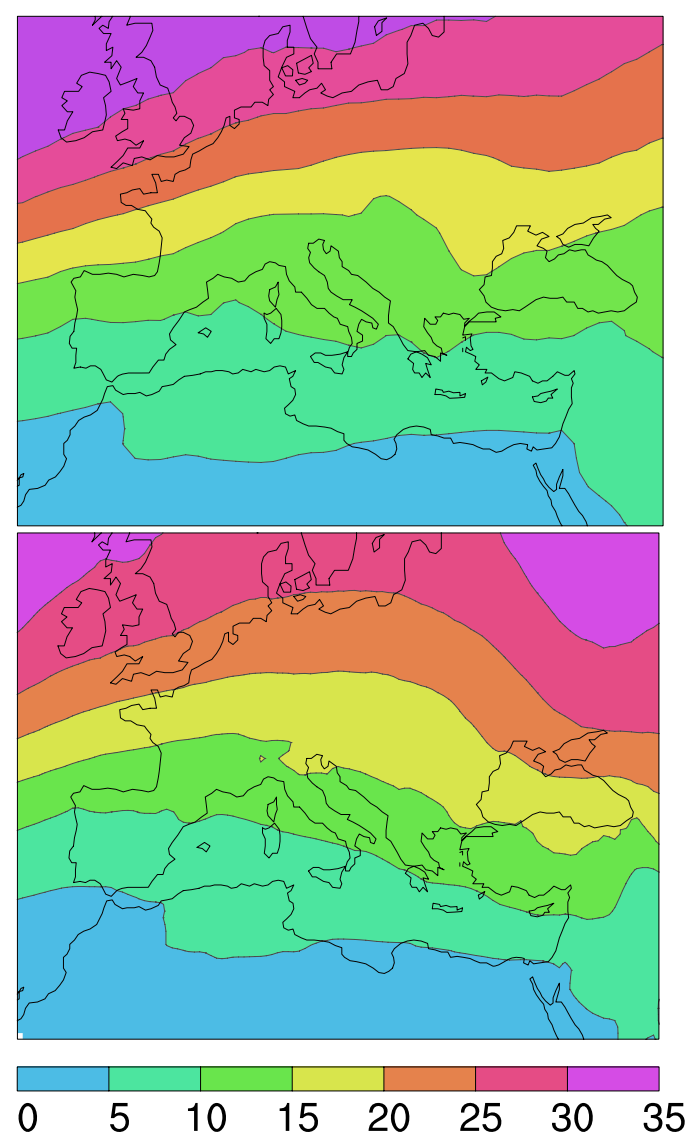

Fig. 3. Synoptic signal according to the ERA-40 data (top) and to the CTR simulation of the RegCM model (bottom). Units: hPa

across south-eastern Europe. It will be shown in the next Sect. 3 that the number of cyclones at the southern border of in this area is correlated with the precipitation over Greece and Turkey. Such overestimation, combined with the underestimation of precipitation, suggests that eastern Mediterranean cyclones produce less rain in the model simulation than in reality. Otherwise, the frequency of cyclone centers is roughly correct over large parts of the domain.

Features characterizing the Mediterranean region are reproduced by the model results in Figs. 3 and 4. The map of the winter synoptic signal (Fig. 3) shows the storm track intensification on the lee of the Alps and Atlas Mountain. The effect of the mountain ridges at the northern Border of the Mediterranean region is responsible for the number of cyclone centers along the North and East coast of the basin in Fig. 4. However, the tracking algorithm has been applied to the band-pass filtered fields, so that the cyclone trajectory features differ from those that would be identified in the original SLP fields. The $15 \mathrm{hPa}$ threshold has been adopted for Fig. 3 in order to include only intense cyclone, likely to contribute significantly to the precipitation monthly total.

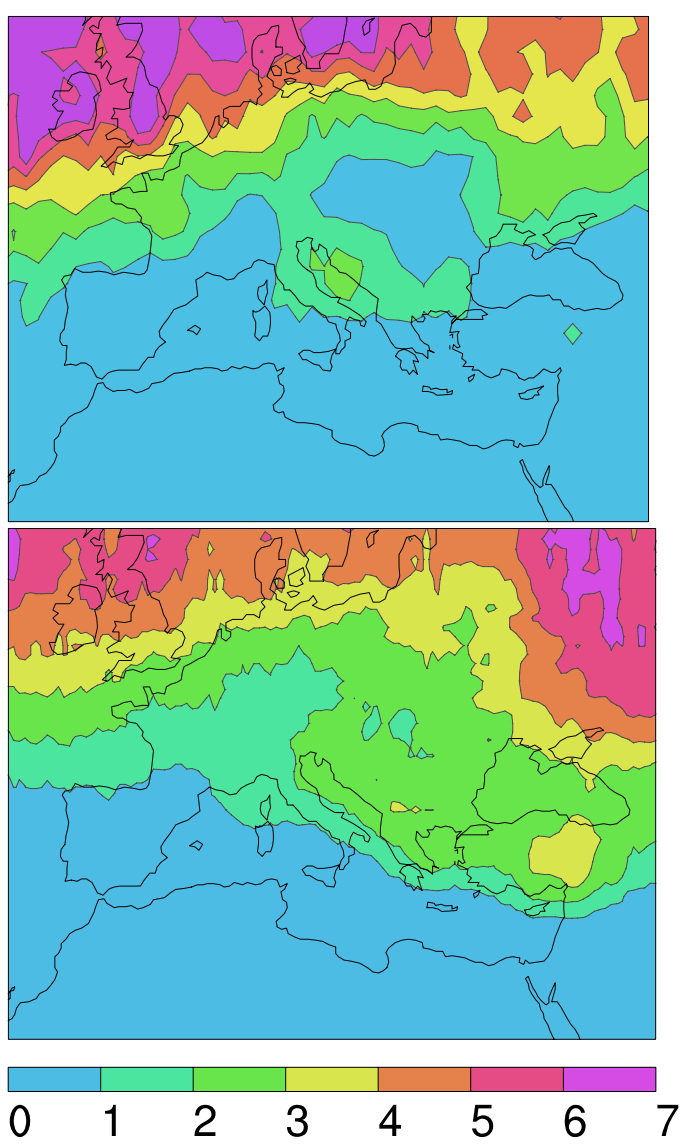

Fig. 4. Cyclone (deeper than $15 \mathrm{hPa}$ ) frequency according to the ERA-40 data (top) and to the CTR simulation. Units: $10^{8}$ number of minima km ${ }^{-2}$ month $^{-1}$. Data have been smoothed on squared areas with size 3 and 11 grid points for ERA-40 and CTR, respectively.

\section{Climate change signal in the $\mathrm{RegCM}$ simulations}

The winter precipitation climate change in the RegCM simulations substantially confirms the results of the MGME analysis ${ }^{1}$ and it shows contrasting changes in the Northern part, projected to become wetter, and the southern part, projected to become drier. Changes increase with the emission level (they are larger in the A2 than in the B2 scenario, where they are significant only in small areas) and are particularly significant in the A2 scenario, being positive over the Alps and the northern Adriatic coast on one hand, and negative at the Mediterranean coast of Turkey and of Middle east, on the other hand. Figure 5 shows the statistically significant changes at the $90 \%$ confidence level according to the MannWhithey test.

\footnotetext{
${ }^{1}$ The B2 scenario used in this study is not available in the MGME dataset. However, note that B1 and B2 are similar, with 550 and $600 \mathrm{ppm} \mathrm{CO}_{2}$ concentration in 2100 , respectively.
} 


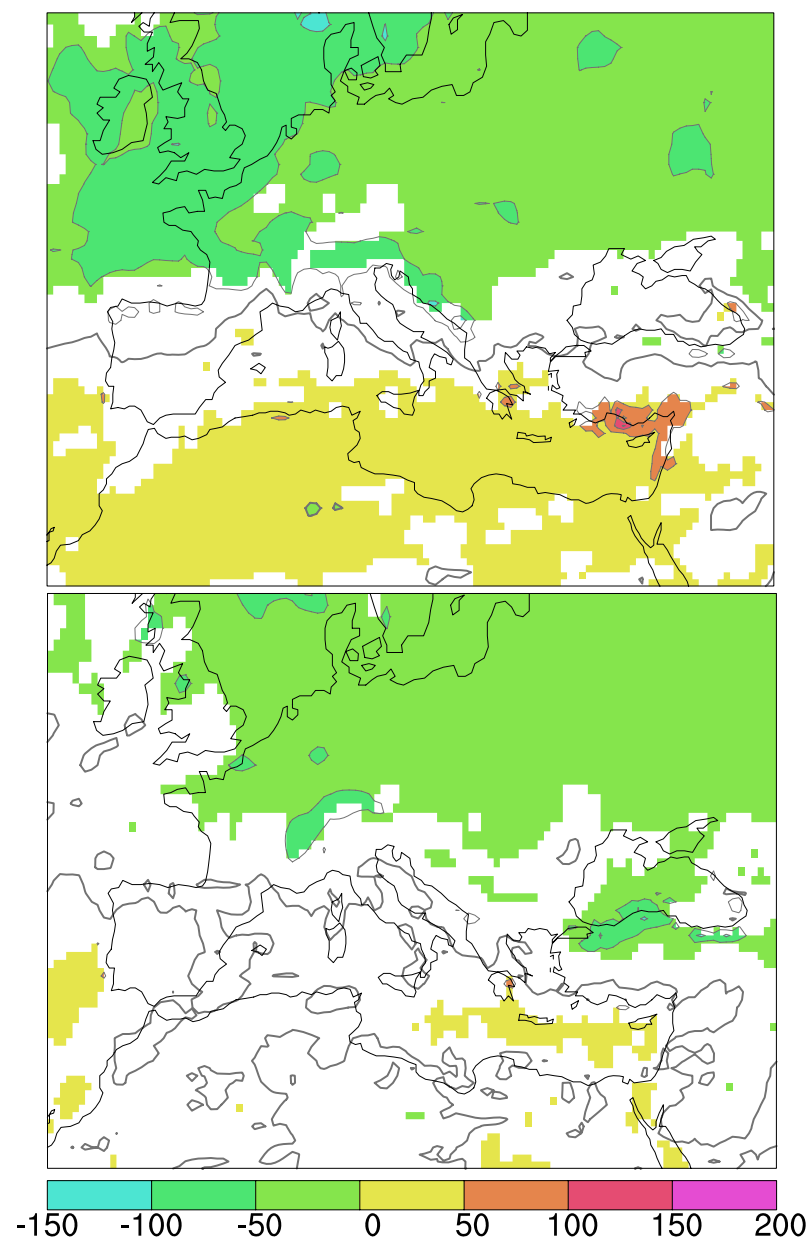

Fig. 5. Winter precipitation climate change signal. Top: CTR minus A2 scenario. Bottom: CTR minus B2 scenario. Positive values denote drier conditions in climate scenarios. In the colored areas changes are statistically significant at the $90 \%$ confidence level according to the Mann-Whitney test. Units: mm.

Also for cyclone activity the Mediterranean is a transition region with an intensification on its north-western area and a reduction over the eastern area, both as synoptic signal and number of cyclone centers are concerned (Figs. 6 and 7). In Fig. 7 only minima deeper than $15 \mathrm{hPa}$ are included. Note that, however, the area where the largest intensification of cyclone activity takes place is outside the Mediterranean and it is associate with an intensification of the mid-latitude storm track over the north-east Atlantic.

These changes of precipitation and cyclone activity are coherent. It is well known that the passage of a cyclone is associated with rain. In the Mediterranean region this is often associated to the advection of humid air against the slopes surrounding the basin. In fact, it has been shown that almost all intense rain events are in coincidence with the presence of a cyclone, positioned so that its circulation advects humid air to the location where precipitation occurs (Jansá et al., 2001).

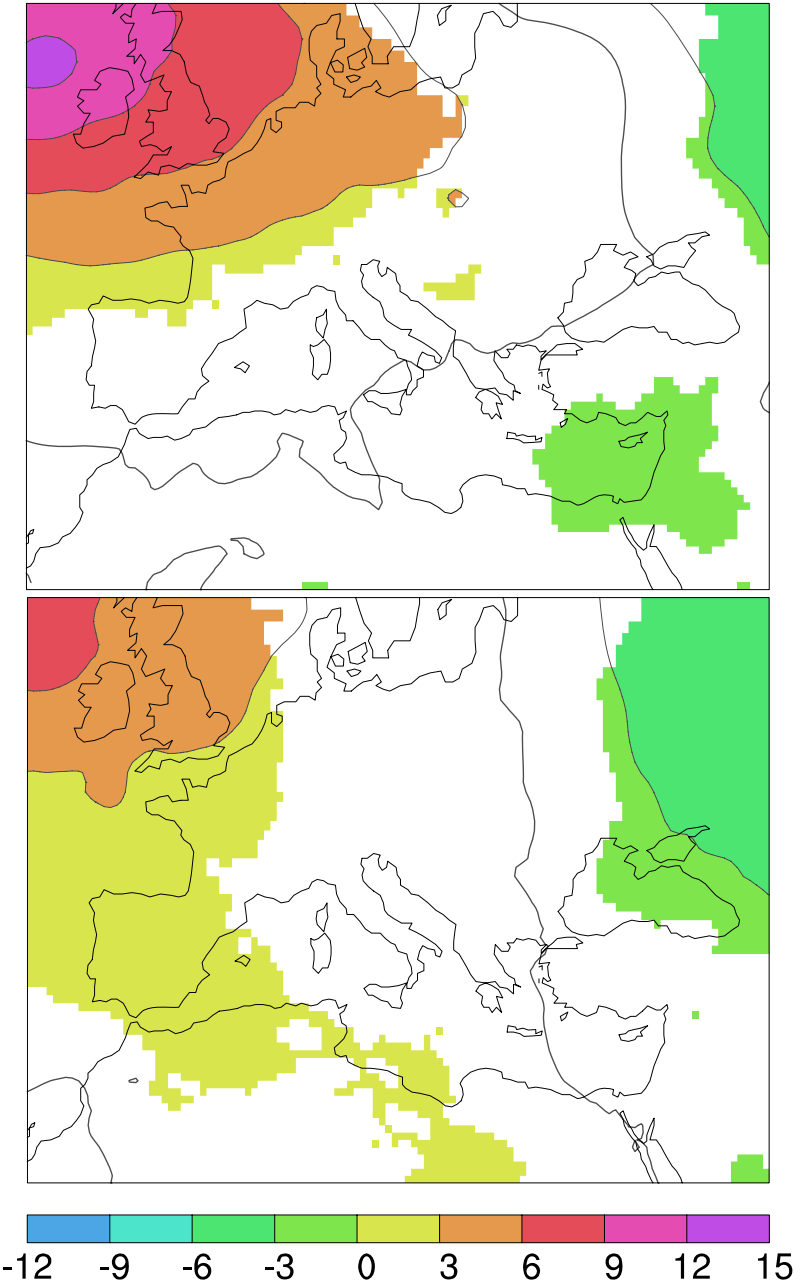

Fig. 6. Synoptic signal. Top: A2 minus CTR scenario. Bottom: B2 minus CTR scenario. Positive values denote larger synoptic signal in climate scenarios. In the colored areas changes are statistically significant at the $90 \%$ confidence level according to the Mann-Whitney test. Units: HPa.

The strong link between position of cyclones and precipitation is confirmed computing the Spearman rank-correlation of total seasonal precipitation in selected areas with synoptic signal and frequency of cyclones deeper than $15 \mathrm{hPa}$ for the CTR simulation. The geographical distribution of the cyclone activity responsible for winter precipitation on the continental part of Italy (including the southern side of the Alps) and the Croatian coast of the Adriatic Sea is shown in Fig. 8 . The seasonal value of precipitation in these two areas (where it is projected to increase) is correlated with the synoptic signal and the number of central pressure minima over the western Mediterranean and western Europe (Fig. 8). The Mediterranean coast of Turkey and the eastern coast of the Mediterranean (where the winter precipitation is projected to diminish) show a different pattern: precipitation over those 


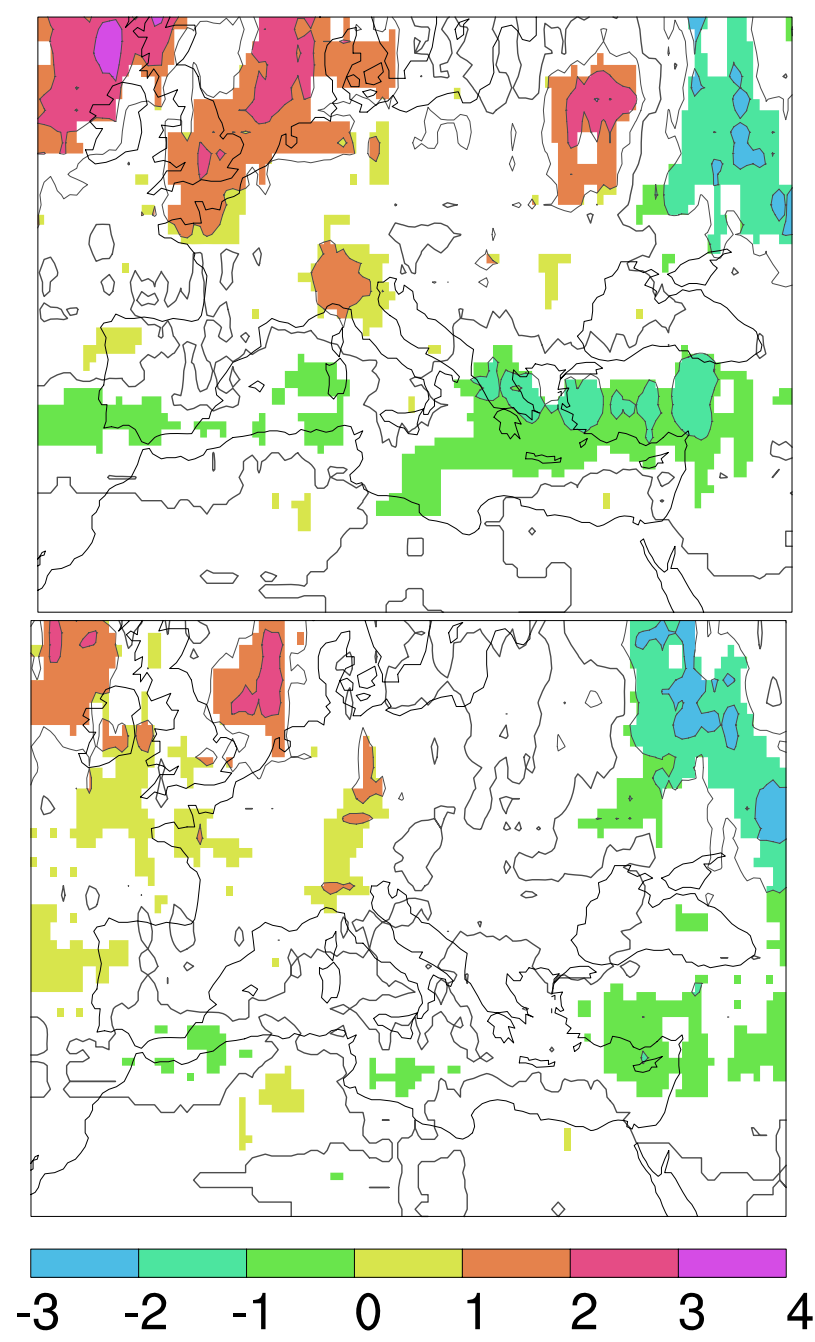

Fig. 7. Cyclone frequency change signal (considering only cyclone minima deeper than $15 \mathrm{hPa}$ ). Top: A2 minus CTR scenario. Bottom: B2 minus CTR scenario. Positive values denote higher frequency in climate scenarios. In the colored areas changes are statistically significant at the $90 \%$ confidence level according to the Mann-Whitney test. Units: $10^{8}$ number of minima $\mathrm{km}^{-2}$ month $^{-1}$.

two regions is correlated with synoptic signal in a region including the whole Mediterranean and north Africa and with the frequency of cyclone centers along the northern coast of the Mediterranean (Fig. 9). Therefore, the comparison between Figs. 8 and 9 shows the different positions of cyclone centers and of cyclone activity areas that produce rain in the northern and south-eastern coasts of the Mediterranean.

Using the spatial distribution of the correlation for interpreting the climate change signal shown in Figs. 5-7 brings to the conclusion that the reduction of cyclone activity and number of cyclones inside the Mediterranean region (and mainly in its eastern part) is responsible for the negative change of precipitation in its eastern part. The positive

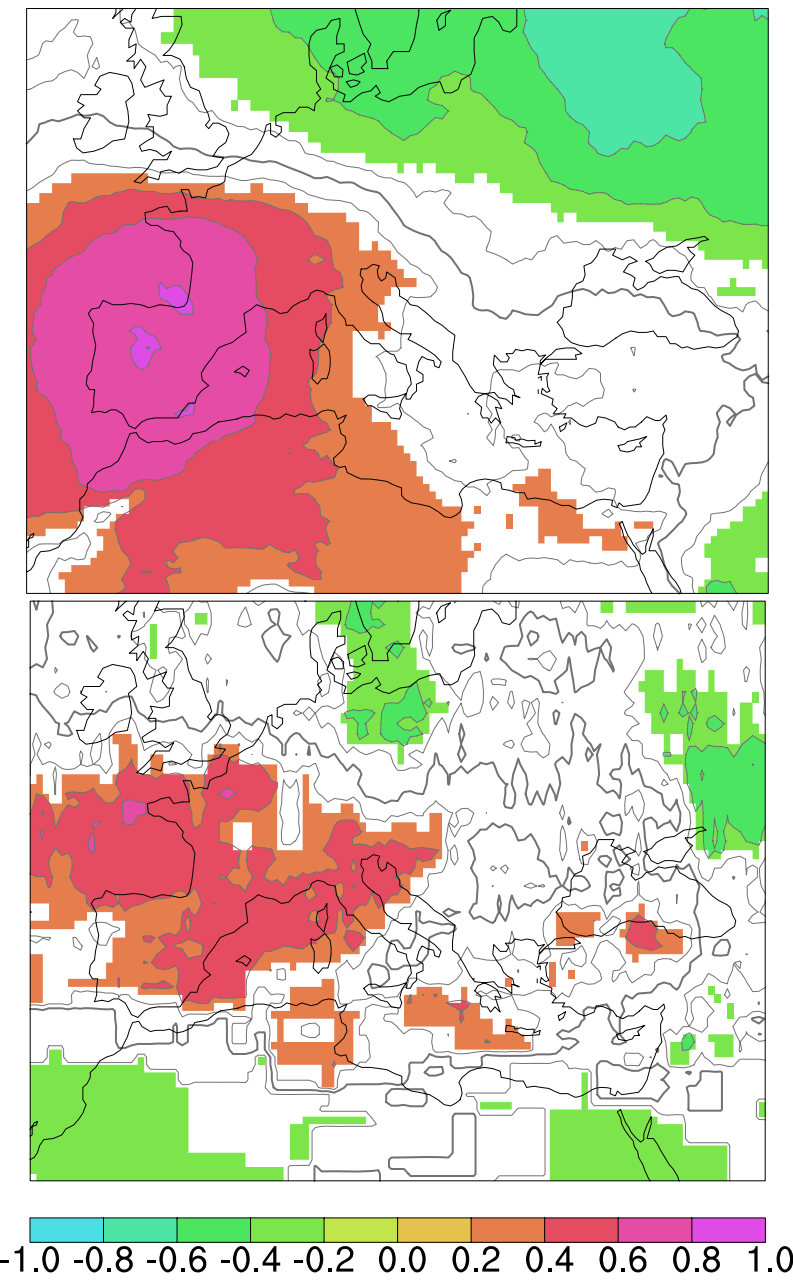

Fig. 8. Spearman Rank correlation of the seasonal precipitation at the Croatian coast of the Adriatic Sea and over the continental part of Italy with the synoptic signal (top) and with the frequency of cyclone centers deeper than $15 \mathrm{hPa}$ (bottom). In the colored areas correlation is statistically significant at the $90 \%$ confidence level.

change in the northern part of the Mediterranean region is instead caused by the increased strength of the mid-latitude storm track occurring mostly outside the region itself.

\section{Conclusions}

The analysis of regional climate simulations of the A2 and B2 scenario confirms the global MGME results and it shows wetter winter conditions at the northern boundary of the Mediterranean region and drier along the southern and eastern coast of the basin. A purpose of this paper is to explain such changes in the precipitation field (Fig. 5) on the basis of changes in synoptic signal (Fig. 6) and cyclone frequency (Fig. 7) using the respective correlation fields shown in Figs. 8 and 9. 


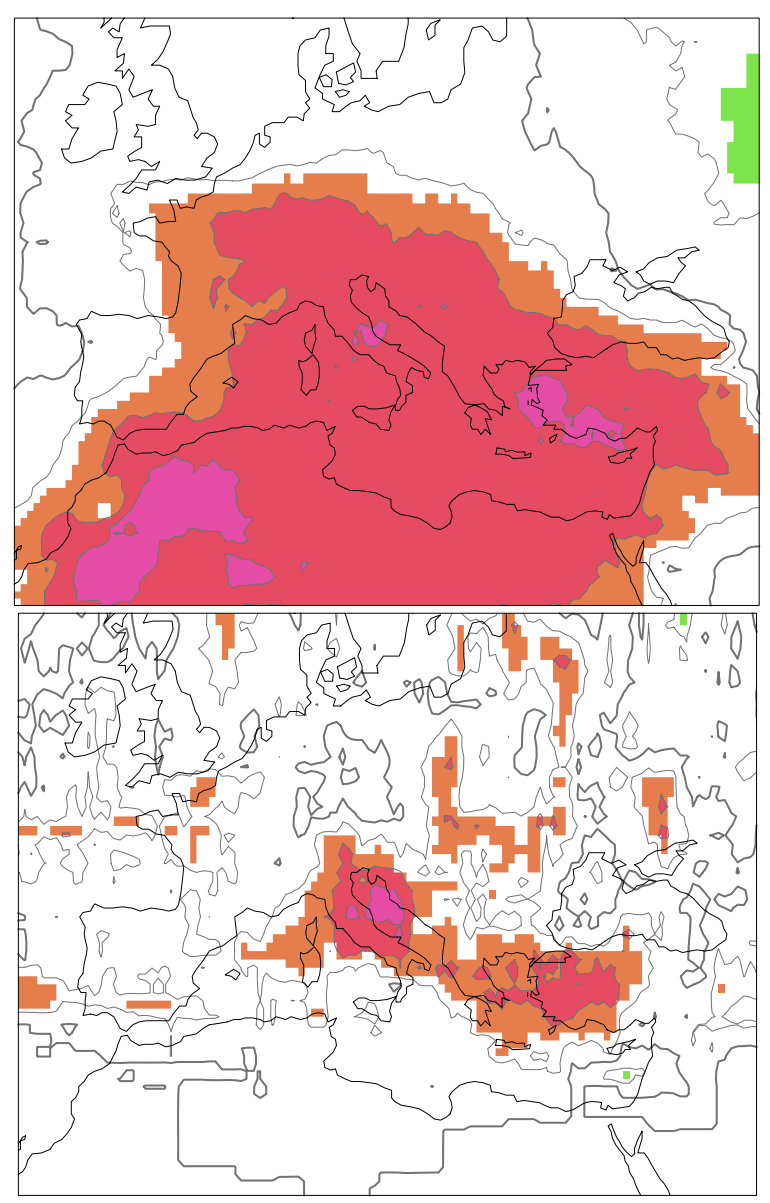

$\begin{array}{lllllllllllllll}-1.0 & -0.8 & -0.6 & -0.4 & -0.2 & 0.0 & 0.2 & 0.4 & 0.6 & 0.8 & 1.0\end{array}$

Fig. 9. Spearman Rank correlation of the seasonal precipitation at the Turkish and Eastern Mediterranean coast with the synoptic signal (top) and with the frequency of cyclone centers deeper than $15 \mathrm{hPa}$ (bottom). In the colored areas correlation is statistically significant at the $90 \%$ confidence level.

The high resolution of the RegCM simulation allows the identification of cyclones and the evaluation of the climate change signal. Cyclone activity is projected to become weaker over the eastern Mediterranean and stronger in the north-western areas. In fact, the north western Mediterranean is partially affected by the intensification of the mid-latitude storm-track which occurs over central and western Europe in the scenario simulations.

The spatial distribution of the correlation of the precipitation with the synoptic signal and with the frequency of cyclone minima shows that, on one hand, the precipitation at the south-eastern coast of the basin is linked to the cyclonic activity inside the basin, and, on another hand, the precipitation in the northern part is linked to the cyclonic activity over western Europe. Therefore, the changes of cyclone activity and of precipitation shown by the RegCM simulations are consistent.
This analysis shows that the response of the Mediterranean region to climate change is not necessarily homogeneous and it is conditioned by changes of intensity and position of the mid-latitude storm track. Since future climate scenarios produce an intensification and a northward shift (away from the Mediterraean) of the mid-latitude storm track this has contrasting effect in different areas within the Mediterranean. The increased intensity of the storm track prevails in the north Mediterranean areas producing an increased winter precipitation. The effect of its shift prevails in the southeastern areas, for which the Mediterranean itself is a main source of moisture, and where the reduced cyclonic activity results in a diminished precipitation at the coast.

Acknowledgements. The authors thank X. Bi for his help with the graphics and U. Boldrin for his contribution to the programs used in this study.

Edited by: P. Alpert, H. Saaroni, and E. Heifetz

Reviewed by: two anonymous referees

\section{References}

Giorgi, F., Bi, X., and Pal, J. S.: Mean, interannual variability and trends in a regional climate change experiment over Europe. Part I: Present day climate (1961-1990), Clim. Dyn., 22, 733-756 2004a.

Giorgi, F., Bi, X., and Pal, J. S.: Mean, interannual variability and trends in a regional climate change experiment over Europe. Part II: Future climate scenarios (2071-2100), Clim. Dyn., 23, 839$858,2004 b$.

Giorgi, F. and Lionello P.: Climate Change projections for the Mediterranean region, Global Planet. Change, accepted, 2007.

Jansà, M. A., Genovès, A., Picornell, M. A., Campins, J., Riosalido, R., and Carretero, O.: Western Mediterranean cyclones and heavy rain. Part 2: Statistical approach, Meteorol. Appl., 8, 43-56, 2001

Lionello, P., Dalan, F., and Elvini, E.: Cyclones in the Mediterranean Region: the present and the doubled $\mathrm{CO}_{2}$ climate scenarios, Clim. Res., 22, 147-159, 2002.

Lionello, P., Bhend, J., Buzzi, A., Della-Marta, P. M., Krichak, S., Jansá, A., Maheras, P., Sanna, A., Trigo, I. F., and Trigo, R.: Cyclones in the Mediterranean region: climatology and effects on the environment, in Mediterranean Climate Variability, edited by: Lionello, P., Malanotte-Rizzoli, P., and Boscolo, R. Elsevier, Amsterdam, The Netherlands, 324-372, 2006.

Lionello, P., Boldrin, U., and Giorgi, F.: Future changes in cyclone climatology over Europe as inferred from a regional climate simulation, Clim. Dyn., doi:10.1007/s00382-007-0315-0, 2007.

New, M. G., Hulme, M., and Jones, P. D.: Representing twentieth century space time climate fields. Part II: Development of a 1901-1996 mean monthly terrestrial climatology, J. Climate, 13, 2217-2238, 2000.

Simmons, A. J. and Gibson, J. K.: The ERA-40 Project Plan, ERA40 Project Report Series n. 1, 2000. 